Paiva, N.V.M.; Araújo, M.V.P. Gestão participativa e ecoturismo em Unidades de Conservação: a voz da comunidade através do Conselho Gestor. Anais do IX Congresso Nacional de Ecoturismo e do V Encontro Interdisciplinar de Turismo em Unidades de Conservação. Revista Brasileira de Ecoturismo, São Paulo, v.6, n.4, nov-2013, pp.11-26.

\title{
Gestão participativa e ecoturismo em Unidades de Conservação: a voz da comunidade através do Conselho Gestor
}

\section{Participatory management and ecotourism in protected areas: the voice of the community through the Management Council}

\author{
Naia Valeska Maranhão de Paiva, Maria Valéria Pereira de Araújo
}

\begin{abstract}
RESUMO
Este artigo problematiza a consolidação da gestão participativa em Unidades de Conservação que apresentam o ecoturismo como principal atividade - através do Conselho Gestor da área protegida. Objetiva-se compreender a participação da sociedade e a representatividade do turismo sob a ótica da criação e gestão de Unidades de Conservação(UC) por meio dos conselhos gestores, exemplificada através da Área de Proteção Ambiental dos Recifes de Corais (APARC), localizada no Rio Grande do Norte, onde o ecoturismo se apresenta de maneira relevante, através de mergulhos nos recifes de corais, representando uma das principais atividades econômicas da região, principalmente no Distrito de Maracajaú. Para o desenvolvimento deste trabalho utilizou-se uma metodologia qualitativa, transversal, de natureza exploratória e de caso, mediante pesquisa bibliográfica e análise de conteúdo dos instrumentos de gestão da APARC, sendo eles o Decreto de Criação e o Regimento Interno. A presente pesquisa permitiu concluir que a participação ativa da sociedade presente em uma área protegida pode ser realizada através da existência e atuação do conselho gestor, que deve ter suas atribuições e competências bem estabelecidas nos documentos de criação e gestão de uma UC, para que ele possa realmente atuar como instrumento de participação, e ser representativo perante as atividades desenvolvidas no local, exemplificada neste artigo através do ecoturismo, demonstrando também a importância da definição de limites e critérios de utilização desses espaços para que a realização da atividade turística seja desenvolvida de maneira sustentável.
\end{abstract}

PALAVRAS-CHAVE: Gestão participativa; Ecoturismo; Unidade de Conservação; Conselho Gestor.

\begin{abstract}
This article discusses the participative management consolidation in protected areas - ecotourism as main activity - through the Management Council in protected areas. It aims to understand society participation and tourism representativenessfrom the perspective of the creation and management of protected areas (PA) through management councils, exemplified by the Environmental Protection Area of Coral Reefs (APARC), located in Rio Grande do Norte, where ecotourism isconsidered in a relevant way through diving in coral reefs, it's one of the main economic regional activities, especially in the District of Maracajaú. Qualitative methodology was used in this study, cross-sectional and exploratory case through literature search and analysis of content management tools APARC, namely the Decree of Creation and the Bylaws. This research showed the active participation of society present in a protected area can be accomplished through the suportand activity of the management council, which must have their responsibilities and authority well established in the creation's documents and management in Conservation Unit, so it can really act as instrument of participation, and be representative before the activities at the site. Exemplified in this article through ecotourism, showning the importance of setting limits and criteria in these spaces, so tourism can be developed in sustainable way.
\end{abstract}

KEYWORDS: Participative Management; Ecotourism; Protect Areas; Council Manager. 


\section{Introdução}

O assunto participação tem se tornado usual em diversos meios há alguns anos, principalmente no âmbito governamental e social. A gestão participativa pode ser vista como uma maneira capaz de revigorar as políticas públicas de modo a transformar a sociedade atual, possibilitando uma maior equidade social.

No Brasil e em relação à atividade turística, se considerarmos a partir do ano de 2003, quando foi criado o Ministério do Turismo, observa-se que o tema participação é um dos principais pontos discutidos no Plano Nacional de Turismo (PNT), que é o instrumento de gestão das políticas públicas direcionadas a esta atividade. O PNT 2003-2007, referente ao planejamento das diretrizes, ações e metas para o Turismo, propõe um modelo de gestão descentralizada e participativa, devendo atingir até a última instância, o município, local onde de fato o turismo acontece. O Plano concebe este tipo de gestão como um desafio a ser ultrapassado e "sugere" integrações e interlocuções entre os diversos níveis hierárquicos de gestão pública, além de ponderar que as informações contidas nele foram provenientes de discussões e fóruns de diversas "origens", apresentando uma proposta de construção coletiva, entre os governos federal, estadual e municipal, as entidades não governamentais, a iniciativa privada e a sociedade como um todo.

O PNT 2007-2010, que surge com a bandeira da inclusão social como prioridade, compromete-se com a continuidade da descentralização e participação no processo de gestão da atividade turística, e apresenta como primeiro objetivo específico a ser alcançado o de garantir a continuidade e o fortalecimento da Política Nacional do Turismo e da gestão descentralizada.

A inclusão da participação social nos processos de gestão de políticas públicas tem sido observada com maior freqüência nos últimos anos e tende a aumentar à medida que a população torna-se mais consciente de seus direitos $\mathrm{e}$ deveres, e passa a exigir que sua voz seja ouvida. No entanto, o que muitas vezes é observado, é a fragilidade do discurso da gestão nomeada participativa, que pode surgir acobertada por outras intenções, supondo-se real, mas sem que verdadeiramente aconteça.

Relacionado ao tema gestão participativa, Demo (2001) e Souza e Rodrigues (2004) têm escrito que o espaço de democracia e de participação deve ser buscado, conquistado, construído e não somente aceitar que o Estado seja o único agente do processo de planejamento.

Para que a participação ocorra de maneira efetiva é necessário que haja gestão pública, comprometida com o bem-estar da comunidade e capaz de compreender 0 atual estágio de democracia originada de uma sociedade mais articulada e ciente de sua força política.

Há autores, como Dias (2008), que defendem que a participação só será bem sucedida se ocorrer em dimensões menores, como regiões ou municípios, caso contrário, consideram um mito a incorporação de uma sociedade no processo de 
participação.

Sobre esse assunto Fischer (2007) ressalta que a atual perspectiva de desenvolvimento baseia-se na idéia da sustentabilidade e numa visão integrada dos aspectos sociais, econômicos, políticos, culturais e ambientais inerentes a qualquer local, pressupondo a articulação dos atores sociais das diversas esferas.

Beni (2006) destaca que somente por meio do sentimento de coresponsabilidade da comunidade perante a participação nos processos é que os resultados positivos poderão surgir.

Pesquisas têm demonstrado que a participação da comunidade no processo de gestão tem alcançado resultados positivos quando há o sentimento de pertencimento e propriedade do espaço que será administrado, sendo também mais fácil obter o apoio da comunidade quando há seu envolvimento no referido processo (REID; MAIR; GEORGE, 2004; MARTÍNEZ, 2008; YATES; STEIN; WYMAN, 2010).

E a inclusão da comunidade sendo um dos pilares do turismo sustentável, caracteriza na gestão participativa um equilíbrio entre o desenvolvimento da atividade turística e a preservação ambiental, a viabilidade econômica e a equidade social (ANSARAH, 2004; MAGALHÃES, 2002; SWARBROOKE, 2002).

No que se refere à gestão participativa em áreas protegidas foi constatado avanços após o ano 2000, já que alguns documentos legais foram promulgados, tais como o Sistema Nacional de Unidades de Conservação da Natureza (SNUC) em 2000, o Plano Nacional de Áreas Protegidas (PNAP) em 2006, entre outros instrumentos, que trouxeram à tona a questão da participação social, refletindo alguns anseios da comunidade. Tais documentos e demais instrumentos legais criados, serviram de referência na implementação da gestão participativa na criação, planejamento e gestão de Unidades de Conservação (UC).

O Sistema Nacional de Unidades de Conservação da Natureza (SNUC) foi instituído em 18 de julho de 2000 por meio da Lei Federal 9.985, constituindo-se assim a primeira normatização nacional das áreas naturais protegidas por lei. Em seu artigo 5ㅜㅗ inciso III, é assegurada a participação efetiva das populações locais durante todo o processo mencionado acima, da criação até a gestão de uma UC. Neste documento, são estabelecidos instrumentos de gestão com participação da sociedade civil, como o conselho gestor (consultivos e deliberativos) envolvendo vários setores da sociedade.

A criação desses conselhos gestores, com o intuito de inserir a comunidade local no processo de gestão de UCs, exerce uma função relevante no controle social da gestão pública, estabelecendo-se como uma ferramenta eficiente de participação da sociedade, tema abordado neste estudo.

Sendo assim, o presente trabalho estuda a gestão participativa em uma UC do Rio Grande do Norte, a Área de Proteção Ambiental dos Recifes de Corais (APARC), através da atuação de seu conselho gestor. Nesta Área de Proteção Ambi- 
ental (APA) o ecoturismo se apresenta como atividade relevante, através de mergulhos nos recifes de corais existentes na área protegida, representando uma das principais atividades econômicas da região.

A criação da Área de Proteção Ambiental dos Recifes de Corais surgiu da necessidade de preservação da área, visto que a mesma, devido sua beleza natural, tornou-se nos últimos anos pólo de atividades turísticas, representando, muitas vezes, ameaças à sustentabilidade ambiental da região (IDEMA, 2012).

A APARC e o seu Conselho Gestor foram criados a partir do Decreto oㅡ 15.476, de 06 de junho de 2001, e compreende a APA mais recente do Estado do $\mathrm{RN}$. E o conselho é o órgão superior que funciona como instância consultiva para o planejamento e gestão desta área, cujo objetivo geral é garantir a gestão democrática da UC.

A APARC compreende a região marinha que abrange a faixa costeira dos Municípios de Maxaranguape, Rio do Fogo e Touros, na porção nordeste do RN, totalizando uma área de 180.000 hectares, e tem como objetivo assegurar o uso devido de seus recursos naturais, garantindo que sejam obedecidas as normas ambientais em vigor, os planos de manejo e de gestão ambiental e o zoneamento orientador do uso. O Instituto de Desenvolvimento Sustentável e Meio Ambiente (IDEMA) é o gestor responsável pela área e que dispõe de Sede Administrativa (ECOPOSTO) localizada no Distrito de Maracajaú, em Maxaranguape, local onde o turismo ocorre com maior intensidade.

A pesquisa obedece a um recorte transversal, haja vista que reflete o momento atual do processo de gestão participativa da APARC, e compreende um estudo de natureza exploratória, e distingue-se também por ser um estudo de caso. Segundo Godoy (1995), o estudo de caso se caracteriza como um tipo de pesquisa cujo objeto é uma unidade que se analisa profundamente. Yin (2005) menciona que a clara necessidade pelos estudos de caso surge do desejo de se compreender fenômenos sociais complexos. Desse modo, este tipo de estudo enquadra-se nesta pesquisa, que também se caracteriza como qualitativa. Segundo Richardson (1985), a metodologia qualitativa pode descrever a complexidade de um determinado problema, analisar a interação de certas variáveis, compreender e classificar processos dinâmicos vividos por grupos sociais.

O presente trabalho utilizará análise e tratamento de dados secundários, adotando-se a análise de conteúdo dos instrumentos de gestão da APA, sendo eles o Decreto de Criação e o Regimento Interno.

Antes de prosseguir com a análise dos dados mencionados é importante fazer uma breve contextualização sobre a relação turismo e participação, e sobre conselho gestor. 


\title{
Turismo e gestão participativa
}

A relação entre turismo e participação pode ser observada mediante a inserção ativa da comunidade no processo de planejamento turístico, que é, de fato, a base do turismo sustentável.

A expressão "turismo sustentável" é citada por Swarbrooke (2002) como sendo aquela que encerra uma abordagem do turismo que reconhece a importância da comunidade local, a forma como as pessoas são tratadas e o desejo de maximizar os benefícios econômicos do turismo para essa comunidade.

De acordo com Ansarah (2004), o turismo sustentável é definido como um modelo de desenvolvimento econômico concebido para melhorar a qualidade de vida da comunidade receptora; proporcionar ao turista uma experiência de qualidade; e manter a qualidade do meio ambiente de que tanto a comunidade anfitriã como os visitantes dependem.

A OMT (2012) define o desenvolvimento turístico sustentável como aquele que tem plenamente em conta os atuais e futuros impactos econômicos, sociais e ambientais, abordando as necessidades dos visitantes, da indústria, das comunidades, do meio ambiente e de acolhimento. E também menciona que:

\begin{abstract}
Desenvolvimento do turismo sustentável requer a participação informada de todos os interessados, bem como uma forte liderança política para garantir uma ampla participação e construção de consenso. Alcançar o turismo sustentável é um processo contínuo e requer monitoramento constante dos impactos, introduzindo as necessárias medidas preventivas e/ou medidas corretivas sempre que necessário (OMT, 2012, s/p).
\end{abstract}

No contexto da discussão referente ao turismo e à gestão participativa, é importante entender que o planejamento e desenvolvimento da atividade turística podem e devem ser influenciados pela comunidade, através da força que o poder de escolha é capaz de representar, e por meio da real inclusão e participação ativa na própria atividade, fazendo com que os gastos sejam minimizados e as melhorias maximizadas. Porém, na realidade, este entendimento não acontece da maneira que deveria, fazendo com que ocorra a manipulação dos instrumentos de gestão pelo lado que se favorece pela não participação da comunidade.

Demo (2001) afirma que participação é conquista, sendo um processo infindável, em um constante vir-a-ser, sempre se fazendo, não existindo participação suficiente, nem acabada, pois a que se imagina completa, nisto mesmo começa a regredir.

A participação é alcançada mediante luta social, dedicação, coragem, pelo anseio em estar presente no processo. Porém, se ela não existe, esta lacuna deve ser considerada como um estímulo para que o processo de conquista se inicie. 
Fischer (2007) evidencia a ausência da dimensão social da gestão, tanto na ação isolada e descontextualizada de gestores governamentais e nãogovernamentais como na perspectiva dos cidadãos que se utilizam de serviços públicos. E ressalta que participação faz parte do processo de gestão social e que é necessária para que esta seja alcançada. $\mathrm{O}$ autor ainda define gestão social como ato relacional capaz de regular processos por meio da mobilização ampla de atores na tomada de decisões, valorizando as estruturas descentralizadas e participativas para alcançar um bem coletivamente planejado, viável e sustentável a médio e longo prazo.

Alguns autores, como Dias (2008), acreditam que o planejamento participativo pode ser considerado um mito, principalmente quando se trata de âmbito nacional, onde não há como incorporar as massas diretamente. No entanto, existem outros mecanismos para essa inclusão, como partidos políticos, organizações não governamentais, organização representativa da comunidade, entre outras. De acordo com o autor, se $o$ alvo for uma cidade, uma região ou um segmento da economia esse tipo de planejamento é possível, e certamente é necessária a participação da comunidade envolvida.

Para Demo (apud DIAS 2008, p.114) a participação é sim realizável, todavia nunca será de modo totalmente satisfatório; esta não é dada, mas criada, bem como não é dádiva, mas sim reivindicação. Assim precisa ser construída, forçada, refeita e recriada.

Demo (2001, p.48) destaca que o "planejamento participativo é possível. Nenhum Estado é tão monolítico, que a participação seja de todo inviável".

Para Beni (2006), em todo e qualquer projeto de mobilização social, o ideal é que a vinculação do público chegue ao nível de corresponsabilidade, pois as pessoas compreendem o quanto a sua participação é importante, sentindo-se responsáveis e acreditando no projeto. Deste modo, os objetivos podem ser alcançados e de maneira duradoura.

No entanto, a participação não resolve todos os problemas, mas é uma opção política que quando inserida no processo de gestão, impulsiona um sentimento de responsabilidade, de cidadania, de compartilhamento e pertencimento a um grupo ou comunidade, capazes de reestruturar a relação entre a sociedade civil e o Estado.

A participação faz parte do processo de descentralização, e no Brasil esse discurso de descentralização da política turística se inicia em 1992, com a regulamentação da Lei $8.181 / 91$, quando são estabelecidas as diretrizes para a implantação de um Plano Nacional de Turismo, apresentando assim, uma profunda alteração, pois o que se observava antes era uma gestão altamente centralizada. $\mathrm{E}$ inicia-se também um fortalecimento da idéia do turismo como fator de desenvolvimento (DIAS, 2008; BENCKER, 1999).

Outros autores também destacaram a questão da descentralização, tais como Beni (2006) que menciona que as mudanças verificadas na década de 1990 nas polí- 
ticas públicas de turismo apresentaram uma feição evolutiva ao ampliar o debate entre governo, iniciativa privada, academia e sociedade.

É também nesta década, mais precisamente em 1996, que é lançado o documento Política Nacional de Turismo: diretrizes e programas - 1996/1999, cuja finalidade foi promover e incrementar o turismo como fonte de renda, de geração de emprego e desenvolvimento socioeconômico do país (BRASIL, apud DIAS, 2008).

A Política Nacional de Turismo, de acordo com o governo, sustentava-se em cinco macroestratégias:

- a implantação de infraestrutura básica e turística;

- a capacitação de recursos humanos para o setor;

- a modernização da legislação;

- a descentralização da gestão do turismo; e

- a promoção do turismo no Brasil e no Exterior.

Sobre a macroestratégia referente à descentralização, Cruz (2002, p.63) menciona:

\begin{abstract}
Essa macroestratégia revela uma postura do poder público federal presente, também, em outros setores da administração pública, de transferência de atribuições - no caso, no que se refere ao turismo - para outros atores sociais (organismos estaduais de turismo, prefeituras, setor privado). Trata-se do que Becker chama de "descentralização controlada", já que o governo federal busca manter o controle estatal da atividade, agora por meio de concessões e negociações.
\end{abstract}

Neste PNT, alguns programas foram desenvolvidos pelo Governo Federal para consolidar as diretrizes estabelecidas, e dentre eles destacam-se:

- Programa Nacional de Municipalização do Turismo - PNMT

- Programa de Ação para o Desenvolvimento do Turismo no Nordeste PRODETUR - NE

- Programa Nacional de Ecoturismo - PROECOTUR

No PNMT, o discurso do processo de descentralização permanece sendo mencionado e visa: implementar um novo modelo de gestão da atividade turística, simplificado e uniformizado, (...), de maneira integrada, buscando maior eficiência e eficácia na administração da atividade turística, de forma participativa (DIAS, 2008).

Em relação ao PNMT, Beni (2006) destaca que o programa foi criado com o objetivo principal de melhorar o produto turístico por meio da conscientização dos municípios e de seus habitantes acerca dos benefícios econômicos que o turismo poderi- 
a aportar, bem como da descentralização das atividades de planejamento.

O PROECOTUR foi criado com o objetivo de desenvolver e propor uma política e um programa destinado à prática do Ecoturismo e o resultado foi o firmamento das Diretrizes para uma política Nacional de Ecoturismo (DIAS, 2008). E dentre as ações estabelecidas para alcançar os objetivos está a "participação comunitária", trazendo a tona novamente a temática da participação.

O governo seguinte, iniciado em 2003, cria o Ministério do Turismo, que foi comemorado por todos aqueles envolvidos com o setor, demonstrando valorização do governo em relação à atividade, e que apresenta como desafio conceber um novo modelo de gestão pública, pautada na descentralização e participação, e propõe um sistema de gestão com vários atores estrategicamente relacionados de modo a atingir até o município, última instância da administração, ocorrendo, inclusive, a criação e constituição de novos atores que farão parte da gestão do turismo.

Em 29 de abril do mesmo ano, o governo divulgou o Plano Nacional de Turismo 2003/2007: Diretrizes, Metas e Programas, que propõe um novo modelo de gestão descentralizada, com a reformulação do Conselho Nacional do Turismo e dos Fóruns Estaduais, e cuja proposta de descentralização é mencionada com veemência, conforme segue (BRASIL, 2003, p.13): "outro instrumento do processo de descentralização será a constituição de 27 fóruns estaduais"; "ainda com parte da política de descentralização, os Municípios serão incentivados a criar os Conselhos Municipais de Turismo".

E por se definir como um instrumento de planejamento de Ministério do Turismo, a participação também é mencionada como parte deste processo, conforme mencionado a seguir (BRASIL, 2003): "este documento está sendo elaborado de forma participativa dentro de um processo permanente de discussão e atualização" (p.15), "a elaboração do Plano Nacional do Turismo com ampla participação da sociedade, são sinais claros de que o turismo é uma das grandes prioridades desse governo" (p.18), "desejamos desenvolver o turismo com base no princípio da sustentabilidade, trabalhando de forma participativa, descentralizada e sistêmica" (p.31).

No governo seguinte, foi lançado o Plano Nacional de Turismo 2007/2010 uma viagem de inclusão, com intuito principal de fortalecer o mercado interno, e que se apresenta como um instrumento de ação estratégica, delineada em programas e metas para os quatro anos de governo, e também como um instrumento de planejamento e gestão que coloca o turismo como indutor do desenvolvimento e da geração de emprego e renda no País.

A proposta de gestão descentralizada e participativa, tão mencionado no PNT anterior, é mantida neste plano, e compreende o primeiro objetivo específico mencionado dentre vários apresentados e que propõe "garantir a continuidade e o fortalecimento da Política Nacional do Turismo e da gestão descentralizada" (BRASIL, 2007, p.16). Um capítulo do programa é destinado exclusivamente para este modelo de gestão, cujo título é Gestão Descentralizada do Turismo e que afirma o seguinte: 
O Plano Nacional de Turismo concebeu e o MTur implementou, com base em sua atuação, um modelo de gestão pública descentralizada e participativa, integrando as diversas instâncias da gestão pública e da iniciativa privada, por meio da criação de ambientes de reflexão, discussão e definição das diretrizes gerais para o desenvolvimento da atividade nas diversas escalas territoriais e de gestão do País, alcançando todas as regiões brasileiras e todos os setores representativos do turismo, de modo a legitimar e a subsidiar a ação ministerial e dos seus parceiros (BRASIL, 2007, p.43).

O PNT também propõe uma gestão capaz de solidificar uma inter-relação entre vários atores da sociedade e o poder público. A passagem abaixo ilustra isso:

A proposta de gestão centralizada do Plano Nacional do Turismo vem fomentando a consolidação de uma rede de entidades e instituições, em todo o território nacional, envolvendo o poder público nas três esferas de governo, a iniciativa privada e o terceiro setor (BRASIL, 2007, p.21).

E esses atores devem se mostrar mais presentes e conscientes do papel que eles representam em todo o contexto da gestão proposta: "Esse conjunto de atores deve ter cada vez mais ampliados e fortalecidos seus espaços de discussão e participação no processo de gestão do desenvolvimento da atividade, em todo o território nacional' (BRASIL, 2007, p.21).

Sendo assim, observa-se que no Brasil há instrumentos de gestão de política pública do turismo que visam consolidar a gestão descentralizada e participativa da atividade, porém, uma condição fundamental para que haja essa consolidação, é que verdadeiramente ocorra a atuação dos indivíduos e grupos locais, discutindo e propondo, se organizando e exercendo sua cidadania, na busca por uma verdadeira democracia Os caminhos da construção desse processo apontam para uma gestão do turismo que se alicerce na sustentabilidade, através da ampla participação da comunidade nas tomadas de decisões, já que a participação mencionada configura-se como um dos pilares do turismo sustentável.

É neste âmbito que surgem os debates relativos à gestão participativa em Unidades de Conservação, por meio da criação de conselhos gestores e outras inclusões sociais como modo de manifestação coletiva e participação.

Até o ano 2000, data da edição do SNUC, as unidades eram administradas exclusivamente pelo Estado. Hoje, devem ser geridas com a participação direta ou pelo menos mais próxima daqueles que podem influenciar na gestão ou que são mais diretamente influenciados, positiva ou negativamente, pela presença de uma UC. Os conselhos gestores passam a se estabelecer como órgãos diferenciados da administração pública, formados em parte pelo Estado e em parte por representantes mais próximos da sociedade civil diretamente envolvida com a UC. 


\section{Conselho Gestor}

O SNUC é conduzido por várias diretrizes, de modo a garantir a concreta participação da população local. Nesse contexto, surgiram os conselhos gestores, que, assim como a organização social das comunidades, são considerados instrumentos de gestão participativa.

Os conselhos gestores das unidades de conservação, ao unir governo e sociedade civil, tornam-se ambientes importantes de discussão e participação dos atores locais nos processos de tomadas de decisões, sendo, portanto, ratificado pela legislação brasileira como o espaço oficial de participação da sociedade na gestão de UCs e tem como propósito principal auxiliar no processo de gestão das áreas protegidas, integrando a representação dos diversos setores da sociedade.

O conselho, presidido pelo chefe da unidade de conservação, deve ter a representação dos órgãos públicos e da sociedade civil o mais paritário possível, considerando as peculiaridades regionais. Assim, devem ser contemplados, quando couber, os órgãos ambientais dos três níveis da Federação e órgãos de áreas afins (turismo), representações da sociedade civil, comunidade científica, organizações não governamentais ambientalistas com atuação comprovada na região da unidade, a população residente e do entorno, população tradicional, proprietários de imóveis no interior da unidade, trabalhadores e setor privado atuantes na região, e representantes dos Comitês de Bacia Hidrográfica (BRASIL, 2011).

A classificação do conselho gestor, como sendo consultivo ou deliberativo, será de acordo com o tipo de UC e está previsto no SNUC. Para as UCs de proteção integral, o conselho será consultivo. E para as UCs de uso sustentável, o SNUC não prevê de maneira explícita para todas as áreas desta classificação, mas somente para as Reservas Extrativistas e as Reservas de Desenvolvimento Sustentável cujos conselhos são deliberativos.

No momento em que o Conselho Gestor é deliberativo, implica dizer que todos os envolvidos podem dirimir sobre a área, acatando as leis que regem a UC. $\mathrm{O}$ fato do conselho ter algum poder de decisão faz com que a comunidade se sinta estimulada e envolvida no processo. Quando é consultivo, que tem como uma de suas funções demonstrar seus pensamentos e ideias, pode acarretar descontentamentos, já que muitas vezes as opiniões não produzem efeitos práticos, fazendo com que os conselhos se tornem burocráticos e pouco ativos.

De acordo com Loureiro, Azaziel e Franca (2007), o fato de o conselho ser deliberativo em UCs não significa risco à integridade do patrimônio, mas a garantia de que todos os envolvidos possam decidir sobre a área, respeitando-se a lei maior que rege uma determinada unidade. O conselho pode deliberar dentro dos limites de uso estabelecidos, o que facilita a motivação e o envolvimento comunitários, pois, para um cidadão é desestimulante utilizar parte de seu tempo apenas manifestando opiniões, sem efeitos práticos. Para o bom funcionamento de um conselho importa mais o status de legitimidade e representatividade que ele alcança. Se ele for mobilizador, sério e democrático, resultará em efetivo poder de intervenção nas políticas e ações soci- 
ais, mesmo sendo consultivo.

Segundo o mesmo autor, existem no Brasil conselhos gestores deliberativos de políticas públicas que, por terem sido criados de "cima para baixo", são instâncias viciadas que reproduzem o favorecimento de determinados setores e o clientelismo. Eles não são condizentes com os princípios preconizados, inerentes à concepção dos espaços de exercício da democracia participativa. Em contrapartida, existem conseIhos e fóruns populares sem existência formal, que alcançam resultados efetivos com base no seu acatamento e na criação de estratégias que garantem a autonomia necessária e o diálogo indispensáveis com os governos.

Sendo assim, independente da classificação do conselho e do poder de decisão que ele representa, e ainda considerando os limites estabelecidos por lei, o importante é que ele seja válido e representativo, capaz de gerar atitudes democráticas e desempenhar ações efetivas. Para que, juntamente com a comunidade, seja capaz de influenciar no manejo racional e equilibrado dos recursos naturais, possibilitando o desenvolvimento de atividades, tais como a visitação pública, podendo ser exemplificada através do ecoturismo, cuja matéria-prima desta atividade é o meio ambiente.

\section{Análise dos dados}

A APARC compreende a APA mais recente do Estado do RN, que também possui as APAs Piquiri-Uma (1990), de Jenipabu (1995) e de Bonfim-Guaraíra (1999), sendo que as duas últimas, assim como a dos Recifes de Corais, apresentam significativa importância turística para o Estado. Porém somente a APARC foi criada após a Lei 9.985/2000 que estabelece critérios e normas para a criação, implantação e gestão das UCs.

A criação da APARC ocorreu em 6 de junho de 2001, através do Decreto $\mathrm{n}$-15.746, que será analisado neste trabalho, e ocorreu mediante necessidade em preservar a área, pois a atividade turística já havia iniciado naquela região e apresentava crescimento desordenado. A área é detentora de grande beleza natural e diversidade biológica, de modo que a procura pelos passeios até os recifes de corais aumentavam e os limites para a exploração desta área deveriam ser estabelecidos com brevidade, com o intuito de manter a biodiversidade e demais atributos ecológicos, e que fosse realizado de uma maneira socialmente justa e economicamente viável. Tal posicionamento pode ser observado no art. $1^{\circ}$ do Decreto de Criação, onde consta a finalidade da criação da APARC:

Proteger a biodiversidade e a vida marinha presentes na área com ocorrência de recifes de corais e suas adjacências; controlar e normatizar as práticas do ecoturismo comercial, do mergulho e da pesca local; desenvolver na comunidade local, nos empreendedores e nos visitantes uma consciência ecológica e conservacionista sobre o patrimônio natural e os recursos ambientais marinhos (RIO GRANDE DO NORTE, 2001, p.1). 
A pesca é uma das principais atividades econômicas desenvolvidas nos municípios que abrangem a área de proteção, cuja realização foi limitada e foram estabelecidos critérios para mantê-la. No decorrer da análise do Decreto de Criação, verifica-se que no art 1ำ também é mencionado que deve ser finalidade da APARC:

\begin{abstract}
incentivar a utilização de equipamentos de pesca artesanal ecologicamente corretos". E que, segundo o art. 3ํㅡㄹ deverá ser permitida "exclusivamente a pesca artesanal, com utilização de linha e anzol". E conforme art. $4^{\circ}$, serão proibidas as seguintes atividades: "Pesca submarina na área de domínio dos Recifes de Corais, através de mergulho livre ou utilizando qualquer equipamento de ar comprimido; captura de peixes ornamentais, lagostas, e qualquer organismos aquático (RIO GRANDE DO NORTE, 2001, p.2).
\end{abstract}

Os limites estabelecidos para a atividade pesqueira, fez com que muitos pescadores, cujo ofício foi passado de pai para filho, buscassem outro tipo de atividade, pois já não conseguiam o seu sustento com a pesca. Muitos deles migraram para o turismo, realizando o transporte de turistas da praia até os recifes de corais, haja vista que na APARC seriam permitidos os seguintes usos além da pesca artesanal com linha e anzol: "visitação aos bancos de recifes de corais; o ecoturismo submarino para a observação dos peixes e dos recifes de coral, utilizando equipamento autônomo ou em apnéia (...)"(RIO GRANDE DO NORTE, 2001, p.2).

No mesmo decreto de criação da APARC foi instituído também o Conselho Gestor, sendo o órgão superior que funciona como instância consultiva para o planejamento e gestão desta Unidade de Conservação, conforme consta no art. 6o: "Fica instituído o Conselho Gestor da Área de Proteção Ambiental - APA dos Recifes de Corais, como instância consultiva para o planejamento estratégico da unidade" (RIO GRANDE DO NORTE, 2001, p.2).

A composição do conselho gestor é descrita no art. $8^{\circ}$ e apresenta o turismo como parte representativa do conselho, que será composto pelo Diretor Geral do IDEMA e por um membro representante de cada um dos seguintes órgãos, entidades e segmentos:

- $\quad$ Secretaria de Estado de Turismo;

- Prefeitura Municipal de Touros;

- Prefeitura Municipal de Rio do Fogo;

- Prefeitura Municipal de Maxaranguape;

- Empresários do turismo que praticam passeios marítimos na área da APA;

- Mergulhadores;

- Organização não governamental ambientalista sediada e atuante nos Municípios abrangidos pela APA;

- Colônia de pescadores sediada e atuante nos Municípios abrangidos pela APA;e

- Associação de moradores das praias dos Municípios de Touros, Rio do Fogo e Maxaranguape(RIO GRANDE DO NORTE, 2001, p.3 ). 
Paiva, N.V.M.; Araújo, M.V.P.

A presidência do conselho gestor atende aos requisitos estabelecidos no art. 15ํㅡㄹ Lei 9.985 do SNUC, que rege: "A Área de Proteção Ambiental disporá de um Conselho presidido pelo órgão responsável pela sua administração (...)" (BRASIL, 2001, p.3).

No Regimento Interno do Conselho, que foi aprovado pelo Conselho Estadual do Meio Ambiente (CONEMA), são apresentados seus objetivos e atribuições, a composição e competência dos conselheiros, sua organização (em relação à estrutura, ao plenário, à presidência, à secretaria executiva, às câmaras técnicas e comissões, e aos conselheiros relatores) e o seu funcionamento (referente às reuniões, desenvolvimento de trabalhos, vistas, votação e atas).

O conselho gestor da APARC pode ser entendido como um instrumento de participação ao observar os artigos $2^{\circ}$ e $3^{\circ}$ de seu Regimento Interno, em que informa 0 seu principal objetivo como sendo o de garantir a gestão democrática da Unidade de Conservação, e uma de suas atribuições como sendo "propor formas de cooperação entre órgãos públicos e a sociedade civil para realização dos objetivos da gestão da área de proteção ambiental', respectivamente (RIO GRANDE DO NORTE, 2009, s/p).

Uma nova estruturação do conselho é apresentada no Regimento Interno, em que permanecem as representações citadas no Decreto de Criação e acrescentando mais sete conselheiros, sendo eles representantes da Gerência Regional do Patrimônio da União - GRPU; do IBAMA/SUPES/RN - ICMBIO/RN; do Ministério da Pesca e Aquicultura - MPA/RN; da Universidade Federal do Rio Grande do Norte; e da Câmara de Vereadores dos municípios de Maxaranguape, Rio do Fogo, e Touros. Essa inclusão de novos representantes é legítima se o conselho assim decidir, conforme o art. 9o do Decreto de Criação no qual afirma: "poderão fazer parte do Conselho da APARC os órgãos federais com atribuições e atuação na área, bem como organismos privados de âmbito nacional ou regional, cuja participação na gestão da APA seja considerada relevante pelo Conselho" (RIO GRANDE DO NORTE, 2001, p.4).

O discurso da gestão participativa que se espera de um conselho gestor pode ser observado no momento em que os conselheiros, investidos de seus cargos, possuem poderes constituídos legalmente para praticar, em reuniões do Conselho, todos os atos necessários à consecução dos objetivos da APARC, conforme ilustrado no art. $7^{\circ}$ do Regimento Interno, onde são apresentas algumas competências do conselho gestor:

Comparecer às reuniões, em dia, local e hora designados, participar dos trabalhos das Câmaras Técnicas e Comissões, usar da palavra quando Ihe for concedida e propor assuntos para deliberação pelo Conselho Gestor;(...) exercer o direito de votar e ser votado; levar ao conhecimento do plenário qualquer ato ou fato que em seu entender, colida com os objetivos do Conselho Gestor ou com os da APARC; (...) fazer constar em ata, seu ponto de vista discordante, ou do órgão que representa, quando julgar relevante (RIO GRANDE DO NORTE, 2009, p.4) 
As reuniões do conselho gestor, que devem ocorrer bimestralmente em caráter ordinário, é o momento que verdadeiramente deve ocorrer a aplicabilidade da teoria, ou seja, em que a prática deve dar lugar aos escritos, tanto do Decreto de criação, quanto do Regimento Interno. Devem ainda ser públicas e realizadas em local acessível, de modo que todos os interessados nos assuntos da pauta possam assisti-las. O art. 19 do Regimento Interno ilustra bem isso: "Para o desempenho de suas atividades, o Conselho Gestor funcionará por meio de reuniões (...); As reuniões do Conselho Gestor serão públicas, e deverão ocorrer em local de fácil acesso, preferencialmente, dentro do seu território" (RIO GRANDE DO NORTE, 2009, s/p). Na APARC, as reuniões ocorrem na sede do IDEMA, denominada ECOPOSTO, e está localizada dentro da área protegida, no Distrito de Maracajaú, município de Maxaranguape.

$E$ a votação, que também é uma etapa importante no processo de participação, é mencionada no Regimento Interno no art. 22 e 23, respectivamente: "Após, esgotadas as discussões, as matérias serão colocadas em votação pelo Presidente da reunião"; "Terão direito a voto, todos os Conselheiros, titulares ou seus respectivos suplentes (...)" (RIO GRANDE DO NORTE, 2009, s/p). Com a ressalva de que o conselho da APARC possui caráter consultivo e atende a uma hierarquia que, no caso de empate, o voto de qualidade cabe ao Presidente da reunião.

Acima são citados alguns trechos selecionados do Decreto de Criação de APARC e do Regimento Interno do Conselho Gestor e possuem como principal características as aplicações de normas e vigências de gestão de uma área protegida baseada na lei 9.985 do SNUC e que permite um estudo da gestão participativa que se pretende aplicar mediante objetivos, atribuições e funcionamento do conselho, bem como das competências dos conselheiros e que possibilita também verificar de que modo a atividade turística foi regulamentada neste espaço que prima pela preservação ambiental.

\section{Conclusão}

A pesquisa realizada focalizou o tema gestão participativa em unidades de conservação através do conselho gestor e a representatividade do turismo na área protegida, através de uma análise dos documentos de gestão da Área de Proteção Ambiental dos Recifes de Corais, sendo eles o Decreto de Criação e o Regimento Interno.

O roteiro do estudo foi orientado pela perspectiva de contribuir para uma compreensão sobre a gestão participativa em unidades de conservação, e a representatividade do turismo, sob a ótica da criação e gestão de uma área protegida.

Os resultados obtidos permitem demonstrar a importância da definição de limites e critérios bem estabelecidos para a atividade turística desenvolvida em unidades de conservação, de modo que sejam realmente obedecidos por aqueles que usufruem da atividade sem permitir que os anseios mercadológicos se sobreponham ao objetivo principal de uma área protegida. E permite também evidenciar o papel do conselho gestor, como importante instrumento de participação da sociedade, devendo ser comprometido e representativo, através de uma atuação coordenada e justa, de modo a tornar público o debate sobre a formação de espaços de participação como um meio de fortificar a democracia de uma nação. 
Paiva, N.V.M.; Araújo, M.V.P.

\section{Referências Bibliográficas}

ANSARAH, M.G.R. (org). Turismo: como aprender, como ensinar. 2. 3. ed., São Paulo: Senac São Paulo, 2004.

BECKER, B. Políticas e planejamento do turismo no Brasil. In:YÁZIGI, E.;CARLOS, A.F.A.; CRUZ, R.C.A. Turismo: espaço, paisagem e cultura. São Paulo: Hucitec, 1999.

BENI, M.C. Política e planejamento de turismo no Brasil. São Paulo: Aleph, 2006.

BRASIL. Ministério do Meio Ambiente. SNUC - Sistema Nacional de Unidades de Conservação da Natureza. Lei no 9.985, 18 jul 2000. Brasília: MMA, 2011.76 p.

BRASIL. Ministério do Turismo. Plano Nacional de Turismo - PNT 2003/2007 - Diretrizes, Metas e Programas. Brasília: MTur, 2003. 48 p.

BRASIL. Plano Nacional de Turismo - PNT 2007/2010 - Uma viagem de inclusão. Brasília: MTur, 2007. 88 p.

CRUZ, R.C,A. Política de turismo e território. São Paulo: Contexto, 2002.

DEMO, P. Participação é conquista. 5. São Paulo: Cortez, 2001.

DIAS, R. Planejamento do turismo: política e desenvolvimento do turismo no Brasil. São Paulo: Atlas, 2008.

FISCHER, T. O futuro da gestão. Revista HSM Management. São Paulo, n. 64, 2007.

GODOY, A.S. Pesquisa qualitativa: tipos fundamentais. Revista de Administração de Empresas. São Paulo, v. 35. n. 3. mai/jun, 1995.

IDEMA. Unidades de Conservação da Natureza. Disponível em: < $\quad$ http:// www.idema.rn.gov.br> Acesso em: 20 abr 2013.

LOUREIRO, C.F.B.; AZAZIEL, M.; FRANCA, N. Educação ambiental e conselho em unidades de conservação: aspectos teóricos e metodológicos. Rio de Janeiro: Ibase, 2007

MAGALHÃES, C.F. Diretrizes para o turismo sustentável em municípios. São Paulo: Rocca, 2002.

MARTÍNEZ, R.E.R. Community involvement in marine protected areas: The case of Puerto Morelos reef, México. Journal of Environmental Management. 88 (2008) 11511160.

ORGANIZAÇÃO MUNDIAL DO TURISMO. Desenvolvimento sustentável do turismo. Disponível em: < http://www2.unwto.org/>. Acesso em: 19 jun. 2012.

REID, D.G.; MAIR, H.; GEORGE, W. Community tourism planning: A self-assessment instrument. Annals of Tourism Research. Vol. 31, N. 3, pp. 623-639, 2004.

RICHARDSON, R.J. Pesquisa social: métodos e técnicas. São Paulo: Atlas, 1985.

RIO GRANDE DO NORTE. Conselho Estadual de Meio Ambiente. Resolução n. $\cong$ 05, de 19 de agosto de 2009. Dispõe sobre aprovação do Regimento Interno de Área de Proteção Ambiental - APA dos Recifes de Corais. Disponível em: <http://www.idema.rn.gov.br/ contentproducao/aplicacao/idema/entidades ambientais/gerados/

conema atos normativos.asp > Acesso em: 20 abr 2013. 
RIO GRANDE DO NORTE. Decreto n. $¹ 5.746$, de 06 de junho de 2001. Dispõe sobre criação de Área de Proteção Ambiental - APA dos Recifes de Corais. Disponível em: < http:// www.idema.rn.gov.br/contentproducao/aplicacao/idema/unidades de conservacao/ gerados/recifes corais.asp > Acesso em: 20 abr 2013.

SOUZA, M.L.; RODRIGUES, G.B. Planejamento urbano e ativismos sociais. São Paulo: UNESP, 2004.

SWARBROOKE, J. Turismo sustentável: conceitos e impacto ambiental. 3. ed. São Paulo: Aleph, 2002. V. 1.

YATES, G.E.; STEIN, T.V.; WYMAN, M.S. Factors for collaboration in Florida's tourism resources: Shifting gears from participatory planning to community-based management. Landscape and Urban Planning. 97 (2010) 213-220.

YIN, R.K. Estudo de caso: planejamento e métodos. 3. Ed. Porto Alegre: Bookman, 2005.

Naia Valeska Maranhão de Paiva: Universidade Federal do Rio Grande do Norte, Natal, RN, Brasil

E-Mail: naiavaleska@hotmail.com

Link para o currículo Lattes: http://lattes.cnpq.br/2902793440696058

Maria Valéria Pereira de Araújo: Universidade Federal do Rio Grande do Norte, Natal, RN, Brasil

E-Mail: valeriaraujoufpb@gmail.com

Link para o currículo Lattes: http://lattes.cnpq.br/9227834040889428

Data de submissão: 28 de junho de 2013

Data de recebimento de correções: 28 de junho de 2013

Data do aceite: 01 de setembro de 2013

Avaliado anonimamente 